\title{
Avaliación 4.0: \\ Avaliación cooperativa en metodoloxías \\ con aprendizaxe invertida
}

Castro, Paula M.; Dapena, Adriana; Vazquez-Araujo, Francisco J.; Laport, Francisco

Facultade de Informática, Universidade da Coruña.

\section{RESUMO}

A palabra CAMBIO describe claramente a situación da Educación a todos os niveis (primaria, secundaria e superior) na nosa comunidade e fóra dela, polo que nos preguntamos se estamos preparados para este cambio. Vivimos na Sociedade da Información, unha sociedade en constante evolución que transforma tamén a Educación, de xeito que cómpre falar de Educación na Sociedade da Información. Este traballo xorde da vontade duns docentes por cambiar "algo" na súa docencia máis ou menos tradicional. Un dos aspectos máis críticos para os estudantes é, sen dúbida, a avaliación. A avaliación forma parte do proceso de aprendizaxe principalmente para determinar o grao de adquisición de competencias e adaptar o proceso educativo segundo as características do estudante ou grupo de estudantes. A responsabilidade da mesma é tradicionalmente do profesor, co que estamos a excluír 0 alumno deste elemento fundamental da educación. A demanda de roles de avaliación invertidos é crecente, polo que neste traballo propoñemos unha AVALIACION 4.0. Nela, estudantes e profesores comparten o rol de árbitros no proceso de aprendizaxe involucrando de xeito activo os primeiros, non só como deseñadores de probas ou instrumentos de avaliación, senón tamén como co-avaliadores, un rol innovador que, por analoxía coa aula invertida, leva a unha avaliación invertida.

PALABRAS CHAVE: avaliación 4.0; avaliación cooperativa; avaliación invertida; metodoloxía activa 


\section{CITA RECOMENDADA:}

Castro, P.M.; Dapena, A.; Vázquez-Araujo, F.J.; Laport, F. (2019): Avaliación 4.0: Avaliación cooperativa en metodoloxías con aprendizaxe invertida. En De la Torre Fernández, E. (ed.) (2019). Contextos universitarios transformadores: construíndo espazos de aprendizaxe. III Xornadas de Innovación Docente. Cufie. Universidade da Coruña. A Coruña (pág. 175-188).

DOI capítulo: https://doi.org/10.17979/spudc.9788497497121.175

DOl libro: https://doi.org/10.17979/spudc.9788497497121

\section{ABSTRACT}

The word CHANGE clearly describes the state-of-the-art of Education at all levels (primary, secondary and higher) in our community and outside of it, so we are wondering if we are prepared for such a change. We live in the Information Society, which is continuously evolving and Education changes with it. Thus talking about Education in the Information Society is mandatory. This work arises from the willingness of some professors of higher education to change "something" in their more or less traditional teaching. The assessment is definitely the most critical aspect of the learning process from the point of view of students. The assessment determines the degree of acquisition of competences and adapts the educational process according to the characteristics of the student or group of students. The professor is traditionally responsible for that, so students are excluded from that task. The demand for flipping assessment roles is growing, and therefore in this work we propose what we denote 4.0 ASSESSMENT. Both students and teachers will share the role of referees in the learning process by actively involving students not only as designers of assessment tests and instruments but also as coevaluators, an innovative role that takes us by analogy with the flipped classroom to flipped assessment.

KEYWORDS: 4.0 assessment: active learning; cooperative assessment; flipped assessment 


\section{INTRODUCIÓN}

A ensinanza baseada en metodoloxías activas é unha ensinanza centrada no estudante que se converte así nun elemento activo e participativo, fronte ao receptor pasivo clásico e debe estar baseada na experimentación activa, é dicir, na posta en práctica dos conceptos teóricos da aula en situacións próximas á realidade do estudante (Kolb \& Kolb, 2005; Prince, 2004). A experiencia do pedagogo estadounidense Edgar Dale indica que a aprendizaxe máis profunda vén precisamente desta experiencia directa, é dicir, que aprendemos cando realizamos a actividade que desexamos aprender (Dale, 1969). Polo tanto, esta aprendizaxe baseada en proxectos, problemas e casos debe incorporarse pouco a pouco na docencia das nosas materias (Barrows \& Tamblyn, 1980; Boud \& Feletti, 2013; Hmelo-Silver, 2004; Rutten, van Joolingen \& van der Veen, 2012; Thomas, 2000). 0 apoio das Tecnoloxías da Información e Comunicación (TIC) nunha ensinanza cada vez máis virtual é fundamental para a eficacia destas metodoloxías (Cabero, 2006; Moreira, 2010; Salinas, 2004).

Entre estas metodoloxías activas está a aprendizaxe baseada en equipos. 0 traballo en grupo incrementa 0 rendemento individual e fomenta destrezas interpersoais e habilidades sociais, posibilitando unha xestión eficiente de tempo e permitindo a viabilidade de proxectos que, doutro xeito, non poderían abordarse na aula. E dentro do traballo grupal, podemos atopar unha diferenciación moi estendida entre traballo grupal colaborativo e traballo grupal cooperativo, é dicir, entre metodoloxías de aprendizaxe colaborativa e de aprendizaxe cooperativa, respectivamente. Na primeira, tanto a formación dos grupos como a división de tarefas, se a hai, é responsabilidade dos alumnos, fomentando deste xeito a creatividade e a aprendizaxe por descubrimento así como a responsabilidade do alumno non só no seu traballo, senón no resultado final do grupo. Na segunda, é o profesor o que forma os grupos e asigna as tarefas individuais, de xeito que o estudante só é responsable da súa tarefa. Aínda que se poida pensar que claramente a primeira ofrece máis vantaxes que a segunda, a aprendizaxe cooperativa facilita moitísimo a avaliación individual do estudante, que é 
precisamente 0 elemento do proceso educativo do que nos imos ocupar nesta experiencia educativa (Johnson, Johnson \& Smith, 1998; Slavin, 1990).

Os roles de profesor e alumno xa non son tampouco os mesmos e falamos cada vez máis de aulas invertidas. Unha vantaxe indiscutible desta metodoloxía é a flexibilidade producida pola aprendizaxe virtual, que substitúe á clásica ensinanza presencial, creando espazos adaptables ás necesidades educativas do estudante. Pero sen dúbida non é a única, xa que ao liberar recursos temporais na aula posibilita unha maior atención á diversidade e permite incorporar as metodoloxías activas das que falabamos antes, fomentando a participación, a motivación e 0 interese do estudante polos contidos que estamos a impartir (Bergmann \& Sams, 2012; Herreid \& Schiller, 2013; Milman, 2012; Tucker, 2012).

A avaliación forma parte do proceso de aprendizaxe para medir o rendemento e adaptar ou orientar o proceso educativo segundo as características do estudante ou grupo de estudantes. A responsabilidade da mesma é tradicionalmente do profesor, co que estamos a excluír ao alumno deste elemento esencial da educación. Por outra parte, esa aprendizaxe invertida ou flipped learning está a mudar o xeito de ensinar os contidos das nosas materias de grao ou mestrado, facendo que os estudantes sexan os verdadeiros protagonistas da súa aprendizaxe. A avaliación, pola contra, segue a metodoloxía tradicional non invertida. Pódese dicir o mesmo da aprendizaxe cooperativa e a súa aplicación á avaliación. Polo tanto, neste artigo presentamos a nosa experiencia avaliadora nunha materia de mestrado que estamos a impartir na Facultade de Ciencias da Educación da Universidade da Coruña, na que lle outorgamos ao alumno o rol principal e que trata de afondar un pouco máis nos cambios que xa se están a producir pouco a pouco na avaliación da ensinanza superior (Brown \& Glasner, 2003; Dochy, Segers \& Dierick, 2002; Gijbels, Van de Watering \& Dochy, 2005; Kaftan, Buck \& Haack, 2006; Sanmartí, 2007; Segers \& Dochy, 2001).

Este traballo estrutúrase do seguinte xeito. Na sección 2 describimos a nosa experiencia docente, na sección 3 amosamos os seus resultados e na 4 as conclusións da mesma. 


\section{DESCRICIÓN DA EXPERIENCIA}

Nesta sección explicaremos a nosa experiencia docente nunha materia de mestrado.

\subsection{CONTEXTO DA EXPERIENCIA}

A materia obxecto da experiencia é Tecnoloxía para profesorado de Educación Secundaria Obrigatoria (ESO), unha materia obrigatoria de cinco créditos do Mestrado universitario en profesorado de educación secundaria obrigatoria, bacharelato, formación profesional e ensinanza de idiomas, itinerario de Tecnoloxía, da Universidade da Coruña. Este mestrado habilita para o exercicio da docencia e é requisito específico para 0 ingreso nos corpos de profesorado de ensino secundario. 0 grupo de estudantes é pequeno, constituído por 20 persoas aproximadamente.

Os resultados de aprendizaxe establecidos na guía docente desta materia son o coñecemento dos contidos de Tecnoloxía obxecto de ensinanza e aprendizaxe na ESO e dos contextos e situacións da contorna axeitados para a aplicación dos contidos.

Por último, os contidos da materia estruturámolos en dez unidades, que abranguen basicamente os contidos das materias de Tecnoloxía na ESO nos cursos de segundo, terceiro e cuarto, e son os seguintes:

UNIDADE 1: Proceso de resolución de problemas tecnolóxicos

UNIDADE 2: Tecnoloxía e sociedade UNIDADE 3: Enerxía. Máquinas. Mecanismos e estruturas

UNIDADE 4: Electricidade e electrónica

UNIDADE 5: Control e robótica

UNIDADE 6: Pneumática e hidráulica

UNIDADE 7: Técnicas de expresión e comunicación

UNIDADE 8: Materiais de uso técnico

UNIDADE 9: Hardware e sistemas operativos

UNIDADE 10: Tecnoloxías de comunicación. Internet

Táboa 1. Contidos 


\subsection{AVALIACIÓN 4.0}

Na nosa materia propoñemos unha metodoloxía de avaliación cooperativa e invertida: falamos entón dunha AVALIACIÓN 4.0. Entendemos que 0 alumno segue a estar excluído deste proceso e que as metodoloxías activas das que falabamos antes teñen que ser incorporadas tamén a unha das partes máis críticas e importantes para o alumno. A avaliación cooperativa implica a participación activa de todos, alumnos e profesores, no proceso. Non é colaborativa, xa que é o profesor quen fixa os procedementos e criterios de avaliación, pero si é responsabilidade de todos. A avaliación é invertida tamén porque o estudante ten un rol moi importante, participando activamente no deseño de probas, rúbricas ou nos pequenos tribunais ou comités avaliadores dos traballos da aula.

0 procedemento de avaliación é mixto: temos una avaliación formativa continua, periodicamente distribuída ao longo de todo o proceso, e unha avaliación sumativa, á fin do mesmo. Non realizamos avaliación inicial de diagnose ao tratarse dun mestrado, pero si unha enquisa ao comezo sobre a titulación de acceso aos estudos de mestrado para adaptar logo os contidos e as prácticas segundo estes perfís. Tal e como se amosa na figura 1, os instrumentos empregados na avaliación continua son pequenos traballos titorizados periódicos, un traballo colaborativo e presentación do mesmo na aula, e prácticas de simulación e experimentación. Na avaliación sumativa empregamos unha proba escrita de preguntas curtas ou tipo test. Cada modalidade de avaliación ten un peso do $50 \%$ na cualificación do estudante. Establécese tamén como criterio de avaliación que non hai cualificación mínima en ningún deles para conseguir un aprobado (5) na materia, pero esíxese a asistencia ao 80\% das sesións presenciais, só na primeira oportunidade. 


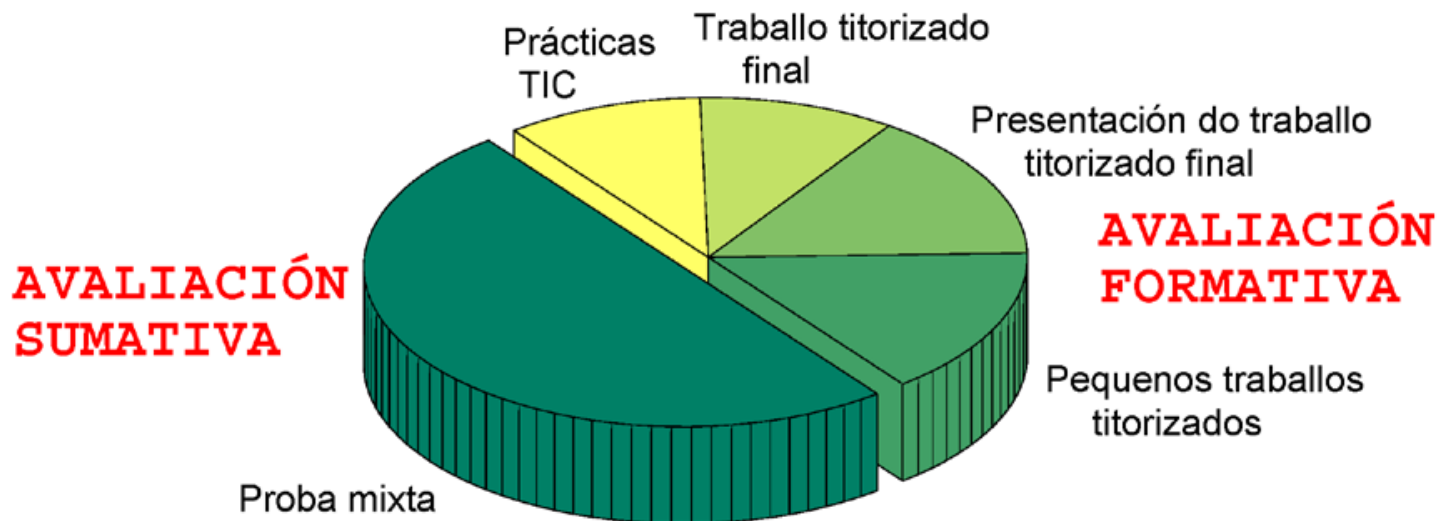

Figura 1. Avaliación 4.0

Nas táboas 2, 3, 4, 5 e 6 que se amosan a continuación describimos brevemente cada unha das metodoloxías activas de avaliación empregadas.

CUANTIFICACIÓN

$10 \%$

\section{METODOLOXÍA BASEADA EN PROXECTOS}

Prácticas de simulación e experimentación (unha de simulación e outra de experimentación) nas que se traballarán as dúas unidades de contidos con máis carencias formativas nas titulacións de acceso coñecidas a través da enquisa inicial.

Táboa 2. Avaliación formativa: Prácticas TIC

\begin{tabular}{|c|c|}
\hline CUANTIFICACIÓN & METODOLOXÍA DE AULA INVERTIDA CON AVALIACIÓN COOPERATIVA \\
\hline $\begin{array}{c}5 \% \text { adicional } \\
\text { (en fase de probas no } \\
\text { curso 2018/19) }\end{array}$ & $\begin{array}{l}\text { Cuestionarios incorporados a vídeos co recurso edpuzzle (Wong, 2018). } \\
\text { Na aula divídese o grupo total en cinco subgrupos. Cada un deles verá } 0 \\
\text { vídeo e acordará unha resposta para cada unha das preguntas } \\
\text { propostas. } 0 \text { vogal do subgrupo expoñerá e defenderá as respostas. Un } \\
\text { pequeno comité formado polos vogais dos outros subgrupos e o } \\
\text { profesor avaliará o traballo de cada un deles, de xeito que o resultado da } \\
\text { avaliación grupal será o que se outorgue para cada un dos membros } \\
\text { dese subgrupo. Usarase a rúbrica para a avaliación da expresión oral } \\
\text { proposta por Laport, Dapena, Castro e Vazquez-Araujo (2018). }\end{array}$ \\
\hline
\end{tabular}

Táboa 3. Avaliación formativa: Pequenos traballos titorizados 


\section{CUANTIFICACIÓN}

$9 \%$

CUANTIFICACIÓN

$25 \%$

\section{METODOLOXÍA BASEADA EN PROBLEMAS}

Modelos xenerativos de enunciado aberto do seguinte xeito: logo de explicar na aula os contidos de cada unidade a modo de visión xenérica do tema (con 18 horas presenciais de sesións teóricas e 10 unidades, nun tempo nunca superior ás dúas horas), 0 alumno debe deseñar unha situación problemática relacionada coa unidade e, na medida do posible, coa realidade cotiá dun estudante de ESO, para a que este estudante debería atopar unha solución aplicando o proceso de resolución de problemas tecnolóxicos no tempo indicado. Existe unha rúbrica de avaliación que ten en conta a complexidade e a orixinalidade do traballo, a súa estrutura e a expresión escrita segundo 0 que propoñen Laport et al. (2018). De acordo coa mesma, o alumno recibe realimentación dos erros cometidos a través de Moodle.

Táboa 4. Avaliación formativa: Pequenos traballos titorizados

\section{METODOLOXÍA DE TRABALLO EN GRUPO COLABORATIVO CON AVALIACIÓN COOPERATIVA}

0 uso da wiki como ferramenta de traballo colaborativo está a incorporarse pouco a pouco na avaliación da aprendizaxe (Adell, 2007; Caple \& Bogle, 2013; Lai \& Ng, 2011; Wheeler, YEoMAnS \& WHEEIER, 2008).

Cada un dos subgrupos estudará algunha das cuestións das unidades de contidos. 0 resultado deste traballo grupal consistía en cursos anteriores nun traballo impreso e a súa presentación oral coma se fose unha sesión real nunha aula dun centro de educación secundaria da nosa comunidade. Este curso 2018/19 muda o formato de entrega do traballo, por motivos de plaxio e de escasa motivación do estudante na redacción do mesmo, a unha wiki colaborativa en Moodle. A rúbrica para a cualificación desta wiki será elaborada polo grupo de estudantes (Quintana \& Cazorla, 2013), debendo conter polo menos as categorías de deseño, navegación, colaboración, recursos e creatividade. Os comités de avaliación outorgarán a cualificación de cada estudante.

Táboa 5. Avaliación formativa: Traballo titorizado final

Avaliando deste xeito pretendemos a inclusión do estudante neste proceso, co que se incrementa a súa motivación e interese pola materia ensinándolle tamén, como futuro docente, esta competencia básica. 


\section{RESULTADOS}

0 nivel de competencia alcanzado polo estudante é verificado por esta avaliación. As competencias da materia amósanse na figura 2.

E, o que é máis importante, con esta experiencia docente fomentamos o desenvolvemento das competencias profesionais docentes, o que denominamos competencia avaliadora.

\section{CUANTIFICACIÓN}

\begin{tabular}{|l|l}
\hline \multirow{5}{56\%}{} & $\begin{array}{l}\text { A elaboración da proba obxectiva final é tradicionalmente } \\
\text { responsabilidade do profesor, pero seguindo a filosofía da aprendizaxe } \\
\text { invertida aplicada a avaliación, propoñemos incluír preguntas elaboradas } \\
\text { polos propios estudantes. Para iso, o alumno elabora de xeito individual } \\
\text { un exercicio curto ou tipo test de cada unha das unidades (6\% da } \\
\text { cualificación final do estudante). } 0 \text { profesor publica en Moodle un } \\
\text { boletín cos exercicios e, logo da revisión a través do foro realizada polos } \\
\text { propios estudantes, a pregunta do exame de cada unidade é elixida de } \\
\text { xeito aleatorio de entre as aproximadamente } 20 \text { contidas en cada un dos } \\
\text { boletíns definitivos (ver Anexo 1). Este exame supón } 0 \text { 50\% da } \\
\text { cualificación final do estudante. }\end{array}$ \\
\end{tabular}

Táboa 6. Avaliación formativa e sumativa: Pequenos traballos titorizados e proba mixta

\section{Competencias específicas}

$>$ Coñecer o valor formativo e cultural das materias correspondentes á especialización.

$>$ Coñecer os contidos que se cursan nos respectivos ensinos.

$>$ Coñecer a historia e os desenvolvementos recentes das materias e as súas perspectivas para poder transmitir unha visión dinámica das mesmas.

$>$ Coñecer contextos e situacións en que se usan ou aplican os diversos contidos curriculares.

\section{Competencias transversais}

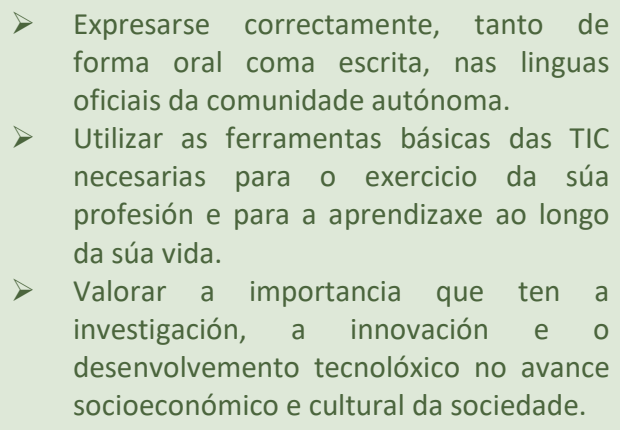

\section{COMPETENCIA AVALIADORA}

Figura 2. Competencias 
En canto aos resultados desta experiencia, existe na literatura un grande número de traballos que reflicten 0 impacto das metodoloxías activas incorporadas na nosa experiencia docente sobre a avaliación dos estudantes (Dochy, Segers \& Sluijsmans, 1999; Freeman et al., 2014; Smith, Dollase \& Boss, 2003). Se analizamos estes resultados no caso desta materia, temos que distinguir entre rendemento académico e satisfacción do estudante. En canto ao primeiro indicador, obtemos unha taxa de éxito, é dicir, unha porcentaxe de alumnos presentados que aproban a materia, dun 100\% nas dúas oportunidades; e en canto ao segundo deles, cuantificado a través das enquisas de avaliación docente da Universidade da Coruña, obtivemos valoracións superiores a 6.5 en todas e cada unha das cuestións relativas á avaliación da materia (sendo 7 puntos a valoración máxima). Incluímos tamén a valoración do volume de traballo esixido ao estudante, porque podería pensarse inmediatamente no posible exceso de carga de traballo desta avaliación se a planificación non é axeitada. Así e todo, a valoración recibida neste punto foi tamén moi positiva, ben porque 0 considera axeitado ou ben porque a motivación co traballo non produce ese sentimento de sobrecarga.

\section{CONCLUSIÓNS}

Neste traballo propoñemos mudar o xeito de avaliar o noso estudante de mestrado facéndoo cooperador activo non só como deseñador de probas e instrumentos de avaliación senón tamén como avaliador das mesmas. A avaliación 4.0 pretende incluír 0 alumno nesta fase do seu proceso de aprendizaxe, tanto na formativa coma na sumativa, e non a súa exclusión como sistematicamente viña acontecendo na avaliación universitaria. Como mencionabamos no traballo, este mestrado habilita para a profesión docente, e como futuros docentes que están a formarse, a adquisición de habilidades avaliadoras é primordial, habilidades que dominarán máis axiña e de xeito máis profundo se se involucran na aprendizaxe coa experiencia directa, como xa explicamos ao comezo deste traballo. Polo tanto, os autores propoñemos neste artigo un cambio de roles tamén na avaliación dos nosos estudantes. 
As liñas de traballo futuras estarán encamiñadas ao desenvolvemento do recurso wiki como recurso dixital de traballo colaborativo dos estudantes e a súa avaliación (deseño de rúbricas a nivel de subgrupo ou grupo total de estudantes, avaliación da mesma polo comité de estudantes...) e 0 estudo da avaliación formativa a través de vídeos educativos empregando a ferramenta edpuzzle.

\section{ANEXO 1: Exemplos de preguntas da proba obxectiva}

Neste anexo amosamos dúas preguntas a xeito de exemplo que os estudantes elaboraron para as unidades 3 e 5 dos contidos da materia no curso 2017/18 (ver táboa 1) e que constituíron as preguntas da proba final respectivas de cadansúa unidade logo dun proceso de selección aleatorio de entre as 20 do boletín da súa correspondente unidade.

- Temos unha engrenaxe formada por dúas rodas dentadas: a primeira delas ou condutora, con $n_{1}$ dentes, e a segunda ou conducida, con $n_{2}$ dentes. Se queremos obter un sistema redutor de velocidade, como debe ser a relación entre o número de dentes de ámbalas dúas rodas?

$$
\begin{aligned}
& n_{1}>n_{2} . \\
& n_{1}=n_{2} . \\
& n_{1}<n_{2} . \\
& \text { Non existe ningunha restrición. }
\end{aligned}
$$

- O compoñente dun robot encargado de transformar os sinais de control en esforzos de potencia recibe o nome de:

Actuador.

Sensor.

Estrutura.

Unidade de control.

\section{AGRADECEMENTOS}

Os autores queriamos agradecer aos demais integrantes do Grupo de Innovación Educativa da Universidade da Coruña en Metodoloxías Activas e Tecnoloxías Emerxentes no Ensino Superior 
(MATEES) polas súas aportacións coas súas experiencias en distintos departamentos, titulacións e centros desta universidade.

\section{REFERENCIAS}

Adell, J. (2007). Wikis en educación. J. Cabero \& J. Barroso (eds.), pp. 323-333.

Barrows, H. S. \& Tamblyn, R. M. (1980). Problem-based learning: An approach to medical education. Springer Publishing Company.

Bergmann, J. \& Sams, A. (2012). Flip your classroom: Reach every student in every class every day. International society for technology in education.

Boud, D. \& Feletti, G. (2013). The challenge of problem-based learning. Routledge.

Brown, S. \& Glasner, A. (Ed.) (2003). Evaluar en la universidad. Problemas y nuevos enfoques. Madrid: Narcea.

Cabero-Almenara, J. (2006). Bases pedagógicas del e-learning. RUSC. Universities and knowledge society journal, 3(1), 1.

Caple, H. \& Bogle, M. (2013). Making group assessment transparent: what wikis can contribute to collaborative projects. Assessment \& Evaluation in Higher Education, 38(2), pp. 198-210.

Dale, E. (1969). Audiovisual methods in teaching. New York: The Dryden Press; Holt, Rinehart and Winston.

Dochy, F. J. R. C., Segers, M. \& Sluijsmans, D. (1999). The use of self-, peer and coassessment in higher education: A review. Studies in Higher education, 24(3), pp. 331-350.

Dochy, F., Segers, M. \& Dierick, S. (2002). Nuevas Vías de Aprendizaje y Enseñanza y sus Consecuencias: Una Nueva Era de Evaluación. Boletín de la Red Estatal de Docencia Universitaria, 2, 2, pp. 13-29.

Freeman, S., Eddy, S. L., McDonough, M., Smith, M. K., Okoroafor, N., Jordt, H. \& Wenderoth, M. P. (2014). Active learning increases student performance in science, engineering, and mathematics. Proceedings of the National Academy of Sciences, 111(23), pp. 8410-8415. 
Gijbels D., Van de Watering, G. \& Dochy, F. (2005). Integrating assessment tasks in a problem-based learning environment. Assessment and evaluation in higher education, 30, pp. 73-86.

Herreid, C. F. \& Schiller, N. A. (2013). Case studies and the flipped classroom. Journal of College Science Teaching, 42(5), pp. 62-66.

Hmelo-Silver, C. E. (2004). Problem-based learning: What and how do students learn? Educational psychology review, 16(3), pp. 235-266.

Johnson, D. W., Johnson, R. T. \& Smith, K. A. (1998). Active learning: Cooperation in the college classroom. Interaction Book Company, 7208 Cornelia Drive, Edina, MN 55435.

Kaftan, J., Buck, G. \& Haack, A. (2006). Using Formative Assessments to Individualize Instruction and Promote Learning. Middle School Journal, 37, 4, pp. 44-49.

Kolb, A. Y. \& Kolb, D. A. (2005). Learning styles and learning spaces: Enhancing experiential learning in higher education. Academy of management learning \& education, 4(2), pp. 193212.

Lai, Y. C. \& Ng, E. M. (2011). Using wikis to develop student teachers' learning, teaching, and assessment capabilities. The Internet and Higher Education, 14(1), pp. 15-26.

Laport, F., Dapena, A., Castro, P. \& Vazquez-Araujo, F. (2018). Acquisition of general competences using project-based learning. 4th International Conference on Higher Education Advances (HEAd'18), pp. 355-364.

Milman, N. B. (2012). The flipped classroom strategy: What is it and how can it best be used? Distance Learning, 9(3), 85.

Moreira, M. A. (2010). ¿Por qué formar en competencias informacionales y digitales en la educación superior?. RUSC. Universities and Knowledge Society Journal, 7(2).

Prince, M. (2004). Does active learning work? A review of the research. Journal of engineering education, 93(3), pp. 223-231. 
Quintana, M. C. S. \& Cazorla, M. J. V. (2013). La utilización de rúbricas para la evaluación del trabajo colaborativo del alumnado en las wikis. Revista de Lingüística y Lenguas Aplicadas, 8(1), pp. 120-128.

Rutten N., van Joolingen W. R. \& van der Veen J. T. (2012). The learning effects of computer simulations in science education. Computers \& Education, 58(1), pp. 136-153.

Salinas, J. (2004). Innovación docente y uso de las TIC en la enseñanza universitaria. International Journal of Educational Technology in Higher Education (ETHE), 1(1). Sanmartí, N. (2007). 10 ideas clave. Evaluar para aprender. Barcelona: Graó.

Segers, M. \& Dochy F. (2001). New assessment forms in problem-based learning: the valueadded of the students' perspective. Studies in higher education, 26, pp. 327-339.

Slavin, R. E. (1990). Cooperative learning: Theory, research, and practice. Prentice-Hall.

Smith, S. R., Dollase, R. H. \& Boss, J. A. (2003). Assessing students' performances in a competency-based curriculum. Academic medicine, 78(1), pp. 97-107.

Thomas, J. W. (2000). A review of research on project-based learning. San Rafael, CA: Autodesk Foundation, 13, pp. 1-45.

Tucker, B. (2012). The flipped classroom. Education next, 12(1), pp. 82-83.

Wheeler, S., YEoMAnS, P. \& WHEEIER, D. (2008). The good, the bad and the wiki: Evaluating student-generated content for collaborative learning. British journal of educational technology, 39(6), pp. 987-995.

Wong, D. (2018). Flipped writing classes using Edpuzzle: lessons learned. Modern English teacher, 27(4), pp. 77-79. 